\title{
Knowledge and Attitude Regarding Eye Donation among Students of Kathmandu University School of Management; A Cross-Sectional Online Survey
}

\author{
Ratna Kumari Maharjan ${ }^{1}$, Nirmal Bajracharya ${ }^{2}$, Shanti Awale ${ }^{3}$ \\ ${ }^{1,3}$ Assistant Professor, Patan Academy of Health Sciences School of Nursing and Midwifery, Sanepa, Lalitpur, \\ Nepal \\ ${ }^{2}$ Nepal Open University, Manbhawan, Lalitpur, Nepal \\ Corresponding Author: Ratna Kumari Maharjan
}

\begin{abstract}
Background: The corneal blindness is the $4^{\text {th }}$ most common cause of blindness all over the world lot of people were waiting for the corneal transplantation but there are only few donors. Availability of potential donors and attitude of eligible donors is the main factor that affects corneal supply.

Method: A descriptive cross sectional research design was carried out among 205 students with the mean age of 22.7 years using self-administered online questionnaire. Descriptive and inferential statistics were used for the analysis of the data. $\mathrm{P}$ value was set at 0.05 .

Result: It has been found that only $4 \%$ of the respondents had good knowledge regarding eye donation and more than $50 \%$ had moderate knowledge and about $40 \%$ had poor knowledge however $90 \%$ know that eye can be donated any age above one year. However, regarding attitude, about $70 \%$ had good attitude. But still 35\% respondents had uncertain about willing to donate eyes after death. Regarding association, only source of information, had significant association with knowledge regarding eye donation. Other variables had no significant association.

Conclusion: Based on the results of this study it has been concluded that most of the respondents had poor knowledge regarding eye donation. However, higher percentage of the respondents had good attitude. Information received from different source had significant association towards knowledge on eye donation but it seemed that though they received information from the media they could not answer correctly. It suggests that there is a need of community awareness program from health professionals.
\end{abstract}

Key Words: Attitude, Eye Donation, Knowledge, Students

\section{INTRODUCTION}

Blindness is defined as visual acuity of less than $3 / 60$, or a corresponding visual field loss to less than 100 , in the better eye with the best possible correction. Visual impairment includes both low vision and blindness. Any profound decrease in vision or blindness due to diseases of the cornea is termed corneal blindness. It is the $4^{\text {th }}$ most common cause of blindness all over the world, accounting for over $5 \%$ of the total blind population. ${ }^{1} \quad$ Corneal visual impairment encompasses a wide variety of infectious and inflammatory eye diseases that cause scarring of the cornea. Significant scarring ultimately leads to functional vision loss. The $4^{\text {th }}$ cause of blindness globally (5.1\%), corneal blindness is one of the major causes of visual deficiency after cataract, glaucoma and age-related macular degeneration (AMD). Ocular trauma and corneal ulcerations are significant causes of corneal blindness. Traditional eye medicines have also been implicated as a major risk factor in the current epidemic of corneal ulceration in developing countries. ${ }^{2}$ 
Corneal transplants are successful site saving operations. More than $90 \%$ of corneal transplant operation is successful and the first successful one was perform on $7^{\text {th }}$ December 1905 by Eduard Zirm in Olomouc Eye clinic. ${ }^{3}$ The corneal transplant is the most common type of human transplant worldwide. The success rate of corneal transplant was $95 \%$. It restores visual function when the impairment cause by the corneal damages to provide acceptable quality of life of people living in that country where corneal transplant was performed. ${ }^{4}$ Corneal blindness is one of the most important causes of blindness in India and this can be treated by corneal transplantation, but due to lack of cornea donation people continue to be on the waitlist. Only $10 \%$ of eye transplantation demands are met due to lack in availability of corneas. There are over 1.5 million people in India who suffer from corneal blindness out of which $80 \%$ cases related to blindness are preventable. ${ }^{5}$

One of the major causes for visual impairment and blindness in the developing world has been attributed to corneal disease. According to the 2010 global blindness estimate, it accounts for around 4\%of the total burden of 50 million. To enhance the awareness of corneal donations further, raising the level of public education on eye donation was the most important first primary step. Eye donation is an act of donating one's eye after his/her death. Only corneal blinds can be benefitted through this process no other blinds. Hence, this pledge of eye donation is purely an act of charity, for the benefit of the society and is totally a voluntary work. ${ }^{6}$ The study done in India, showed that the mean percentage of the knowledge scores among adolescents were $57 \%$, and the mean percentage of the attitude scores among adolescents were $70.5 \%$. There was a positive correlation between knowledge and attitude among adolescents. $^{7}$

The Nepal eye bank at Tilganga institute of ophthalmology is an unprecedented facility in Nepal. The concept of the eye bank was support by the international federation of eye and tissue bank (IFETB) and was started from September 13 ${ }^{\text {th }}, 1994$ AD. The first Donor was Chini Maya Tuladhar and the first corneal transplantation took place on $19^{\text {th }}$. The number of people pledging for eye donation in Nepal eye bank till now is 7, 11,052 . $^{8}$

A study done in Eastern Nepal to find out awareness regarding eye donation among eye health workers. The result showed that $60.5 \%$ participants knew that eyes can be donated after death ideally within 6-8 hours of death.78.5\% respondents believed donated eye gives good sight to blind. Lack of awareness was cited as an important for people not donating eyes among $49.2 \%$ of participants.19.8\% perceived objections from family members followed by dislike of separating eye among $15.7 \%$ respondents and $15.3 \%$ respondents had religious belief. Among religious belief, $11.1 \%$ respondents believed of being born blind in next birth and not going heaven if they donate their eye. ${ }^{9}$

\section{METERIALS AND METHODS}

A descriptive cross-sectional research design was used to assess the knowledge and attitude regarding eye donation among students of Kathmandu university school of management (KUSOM), ward no 8, Pinchhen, Balkumari, Lalitpur Municipality, Nepal.

The participation of this study were all students who studying Bachelor in business administration (BBA) and Master in business administration (MBA). Data collection procedure was done online through Google form, Assuming the high non response rate in online data collection we administered the Google form to all students i.e. 600 though calculated sample size was 377 . However, sample size for the final data analysis was 205 that represents $34 \%$ response rate. Researcher had distributed questionnaire to all students through individual email address. 

university school of management; a cross-sectional online survey.

Where,

$$
\text { Sample size }(\mathbf{n})=\frac{z 2 p q}{e 2}
$$

$\mathrm{n}=$ required sample size

$\mathrm{z}=$ confidence level at $95 \%$

$\mathrm{p}=$ estimated predicted or anticipated rate for a given indicator in the study area $57 \%$

$\mathrm{q}=1-\mathrm{p}$

$\mathrm{e}=$ margin of error at $5 \%$ ( standard value of 0.05)

Sample size $(\mathrm{n})=\frac{1.96^{2} \times 0.57 \times(1-0.57)}{0.05^{2}}=377$ (Heyke M. Chacko, Jasmine Mathew 2014)

Formal permission was taken from the concerned college authority before data collection. The purpose of the study was explained and written consent was taken from each respondent before data collection. Anonymity was assured through mentioning respondents as code number and hiding the identification of respondents and clear instruction was given to respondents not to write their names in questionnaire. Confidentiality was maintained by assuring that provided information was used only for study purpose. The proposal was approved from Nepal Health Research Council (NHRC). The data was collected after ethical approval from NHRC and formal permission was taken from Kathmandu University, School of Management. Data was collected online through using Google form in the personal email. The information regarding the study was given online through Google form by the principal investigator. Students had explained about the study objectives and invited to participate. The approximate time to fill questionnaire was 20 to 25 minutes those who return filled questionnaire was considered having given consent for the study.

The research instrument was developed based on the objectives of the study and was prepared on the basis of extensive literature review. Semi-Structured self-developed self-administered questionnaire was used to measure awareness and attitude of eye donation among college students. The data collection instrument was divided into three parts:

Part I Socio-demographic information (Age, Education, Gender, Ethnicity and Religions)

Part II Knowledge related questions regarding eye donation which consists of 20 questions with multi-response, multiple choice options, 'yes' or ' no' questions and open ended questions where 7 questions are multi responses, 7 questions are multiple choice, 4 questions are 'yes' or 'no' and 2 are open ended questions .

Part III attitude related question towards eye donation which consists 12 items in 3 point Likert scale where 1 denotes Disagree, 2 denotes Neutral and 3 denotes Agree. Eight items are positive statements and 4 items are negative statement.

For knowledge scoring each score of 'one' was given for each correct response and a score 'zero' was given for an incorrect response. Total score ranges from o to 45 . The knowledge was categorized in three categories.

Poor knowledge: score $<50 \%$

Moderate knowledge: score 50-79\%

Good knowledge: score $>79 \%$

Total score of attitude ranges from 12 to 36. Attitude was categorized into two categories: Good Attitude and Poor attitude based on the median value calculated (Hussen MS, Belete GT. 2018).

The content validity of study instrument was maintained by consulting subject experts. Pre-testing among $10 \%$ of the total size that is similar students of BBA, MBA from another college. Necessary modification in the questions was done accordingly. All the data received from the online system were checked for completeness. The data was analysed using SPSS 16 version. Descriptive statistics (frequency, percentage, standard deviation and mean) was used to describe the demographic data and find out the knowledge and attitude level. Inferential statistics (Chi-square test and Fisher's exact-test) was used to determine 
Ratna Kumari Maharjan et.al. Knowledge and attitude regarding eye donation among students of Kathmandu university school of management; a cross-sectional online survey.

association between knowledge and demographic variables.

\section{RESULTS}

Table 1 show that all respondents were from age group 18-31years. The mean age was $22.71 \pm 2.65$ standard deviation. More than half $61.0 \%$ of respondents were studying bachelor, most of the respondents were female $64.9 \%$, Nearly half $45.9 \%$ of the respondents were from Newar ethnicity and more than $80.5 \%$ respondents were Hindu religion whereas $2.0 \%$ were Christian.

Table 1.Socio Demographic Characteristics, $\mathrm{N}=205$

\begin{tabular}{|l|l|l|}
\hline Characteristics & Frequency & Percentage \\
\hline Age & 205 & 100 \\
\hline $\begin{array}{l}18-31 \\
\text { Mean age 22.71 SD } \pm 2.653\end{array}$ & \\
\hline Education & 125 & 61.0 \\
\hline BBA & 80 & 39.0 \\
\hline MBA & 72 & 35.1 \\
\hline Gender & 133 & 64.9 \\
\hline Male & \multicolumn{2}{|l|}{} \\
\hline Female & 94 & 45.9 \\
\hline Ethnicity & 54 & 26.3 \\
\hline Newar & 32 & 15.6 \\
\hline Bramin & 25 & 12.2 \\
\hline Chhetri & \multicolumn{2}{|l|}{} \\
\hline Others & 28 & 13.7 \\
\hline Religion & 165 & 80.5 \\
\hline Buddhist & 4 & 2.0 \\
\hline Hindu & 8 & 3.9 \\
\hline Christian &
\end{tabular}

\section{Respondents Knowledge regarding Eye donation}

Table 2. Meaning of eye donation, part of eye used \&benefit to donate eye, $\mathrm{N}=\mathbf{2 0 5}$

\begin{tabular}{|l|l|l|}
\hline Characteristics & Frequency & Percent \\
\hline Meaning of eye donation & 11 & 5.4 \\
\hline Donation of eyes just before death & 158 & 77.1 \\
\hline Donation of eyes after death & 36 & 17.6 \\
\hline Donation of eyes anytime during life & 21 & 10.2 \\
\hline \multicolumn{3}{|l|}{ The part of eye used for eye donation is } \\
\hline The whole eye ball & 21.2 \\
\hline The cornea(black central part of eyeball) & 105 & 51.3 \\
\hline The retina (innermost layer of eye ball) & 13 & 32.2 \\
\hline Both cornea and retina & 66 & 46.3 \\
\hline Eye donation can benefit to & \multicolumn{2}{|l|}{} \\
\hline $\begin{array}{l}\text { Corneal blind person(blind due to defect } \\
\text { in black part of eyeball) }\end{array}$ & 95 & 7.3 \\
\hline $\begin{array}{l}\text { Retinal blind person(blind due to inner } \\
\text { part of the eye) }\end{array}$ & 15 & 4.4 \\
\hline $\begin{array}{l}\text { Cataract blind person(Motiyabindu in } \\
\text { nepali) }\end{array}$ & 9 & 42.0 \\
\hline Any type of blind person & 86 & \\
\hline
\end{tabular}

Table no 2 shows $77.1 \%$ know eye donation means donation of eyes after death, similarly $51.2 \%$ know that the part of eyes cornea is used for eye donation and only $46.3 \%$ respondents know that corneal blind person is benefit by eye donation

Table 3.1 reveal that knowledge about eye can be donate by people of any age above one year was $88.7 \%$ followed by high blood pressure can donate eye, high blood sugar and people having glasses can donate eyes was $31.9 \%, 27.55 \%$ and $38.2 \%$ respectively.

Similarly knowledge about eye cannot donate by people with infection of cornea was $90.6 \%$ and only $39.9 \%$ know about people with Hepatitis B cannot donate eyes.

According to place for eye donation, almost all $99.0 \%$ of respondents said hospital is the place for donation eyes and only $4.4 \%$ said Graveyard (buried area).

Table 3.1 Knowledge according to criteria for eye donation, $\mathrm{N}=\mathbf{2 0 5}$

\begin{tabular}{|l|l|l|}
\hline Characteristics & Frequency & Percent \\
\hline Eyes can donate by * & 88.7 \\
\hline People of any age above 1 year & 181 & 31.9 \\
\hline People with high blood pressure & 65 & 27.5 \\
\hline $\begin{array}{l}\text { People with high blood } \\
\text { sugar(Diabetes) }\end{array}$ & 56 & 38.2 \\
\hline People wearing glasses & 78 \\
\hline Eyes cannot donate by * & 97 & 47.8 \\
\hline People with HIV/AIDS & 81 & 39.9 \\
\hline People with Hepatitis B & 184 & 90.6 \\
\hline People with infection of cornea & 95 & 46.8 \\
\hline People with blood cancer & 102 & 50.2 \\
\hline Death due to unknown cause & 203 & 99.0 \\
\hline Eye can be donation in * & 29 & 14.1 \\
\hline Hospital & 39 & 19.0 \\
\hline House & 9 & 4.4 \\
\hline Mortuary & \\
\hline Graveyard (buried area) &
\end{tabular}
Note $^{*}$ multiple responses

Table 3.2 reveals that one third $75.1 \%$ know that put wet cotton on eye lids after death and only $11.7 \%$ know that switch off the fan during event of death of person who willing to donate eyes. Maximum $86.3 \%$ of respondents said that Nepal Eye Donation Society is the approachable organisation for eye donation and $67.8 \%$ said eye bank is approachable organisation for eye donation. More than half $59.5 \%$ of the respondents have knowledge that eye should be donate within 6-8 hours after death. Almost all $93.7 \%$ of respondents have knowledge on donation consent can be 
Ratna Kumari Maharjan et.al. Knowledge and attitude regarding eye donation among students of Kathmandu university school of management; a cross-sectional online survey.

given by donor himself or herself when alive and $76.1 \%$ of respondents said that donation consent can be given for deceased person by the donor's family members.

Table 3.2 Knowledge according to criteria for eye donation. $\mathbf{N}=205$

\begin{tabular}{|l|l|l|}
\hline Charecteristics & Frequency & Percent \\
\hline $\begin{array}{l}\text { the event of death of person who } \\
\text { willing to donate eyes will do * }\end{array}$ & & \\
\hline Switch off the fans & 24 & 11.7 \\
\hline Put wet cotton on eye lids & 154 & 75.1 \\
\hline Pillow under the head & 35 & 17.1 \\
\hline Safe from sun light & 129 & 62.9 \\
\hline Approach for eye donation * & & \\
\hline Eye bank & 139 & 67.8 \\
\hline Hospital & 83 & 40.5 \\
\hline Eye specialist & 60 & 29.3 \\
\hline Nepal Eye Donation Society, Till Ganga & 177 & 86.3 \\
\hline Doctors & 25 & 12.2 \\
\hline After death, eyes should be donated & & \\
\hline Within 6-8 hours & 122 & 59.5 \\
\hline Within 10 - 24 hours & 70 & 34.1 \\
\hline Few days later & 7 & 3.4 \\
\hline Any time after death & 6 & 2.9 \\
\hline Consent can give for eye donation by & & \\
\hline Donor by himself or herself when alive & 192 & 93.7 \\
\hline Donors family members & 12 & 5.9 \\
\hline Health worker & 1 & .5 \\
\hline $\begin{array}{l}\text { Consent can give for the eye donation } \\
\text { of deceased person by }\end{array}$ & & \\
\hline No one & 46 & 22.4 \\
\hline Any one & 3 & 1.5 \\
\hline Family member & 156 & 76.1 \\
\hline & & \\
\hline
\end{tabular}

Table 4 knowledge regarding source of information among eye donation, $\mathrm{N}=\mathbf{2 0 5}$

\begin{tabular}{|l|l|l|}
\hline characteristics & Frequency & Percent \\
\hline $\begin{array}{l}\text { Source of information regarding eye } \\
\text { donation* }\end{array}$ & \\
\hline Internet & 106 & 51.7 \\
\hline Newspaper & 4 & 2.0 \\
\hline Television/Radio & 35 & 17.1 \\
\hline Friends and relatives & 46 & 22.4 \\
\hline Health worker & 14 & 6.8 \\
\hline \multicolumn{2}{|c|}{ Note $^{*}$ multiple responses } \\
\hline
\end{tabular}

Table 4 shows that more than half of respondents $51.7 \%$ got information about eye donation from Internet followed by $2.0 \%$ from newspaper, $17.1 \%$ from television/radio, $22.4 \%$ by friends and relatives and $6.8 \%$ by health worker.

Table 5 shows the level of knowledge regarding eye donation. The result indicate that nearly two third of the respondents $(61.5 \%)$ have moderate knowledge, more than one third (34.6\%) of the respondents have poor knowledge and only few of the respondents (3.9\%) have good knowledge.

Table 5 Respondents level of knowledge on Eye Donation, $\mathrm{N}=\mathbf{2 0 5}$

\begin{tabular}{|l|l|l|}
\hline Level of knowledge & Percentage & Frequency \\
\hline Poor knowledge $<50 \%$ & 71 & 34.6 \\
\hline Moderate Knowledge 50-79\% & 126 & 61.5 \\
\hline Good knowledge $>79 \%$ & 8 & 3.9 \\
\hline
\end{tabular}

Regarding the attitude of respondents toward eye donation, table No.6 shows that $89.3 \%$ respondents agree that eye can be donated after death and gives vision to corneal blind people. Almost respondents $93.3 \%$ agree that eye donation is a noble work and $76 \%$ respondents agree that living person pledge to donate eyes. More than half of the respondents $55.6 \%$ willing to pledge eyes and $65.4 \%$ respondents willing to donate eyes after death. Half respondents $50.2 \%$ agreed that eyes are never bought or sold. Almost respondents $95.6 \%$ agreed that awareness regarding eye donation is important.86.8\% respondents disagreed that donation of eye lead to blindness in the next birth and more than half respondents $53.2 \%$ disagreed that all blind people were cured by eye transplantation. $70.7 \%$ of respondents disagreed that during transplantation whole eye is used and $59.5 \%$ respondents disagree that eye donation disfigures the face of donor.

Table 6 Attitude towards Eye Donation, N=205

\begin{tabular}{|l|l|l|l|l|l|l|}
\hline Statement & Agree & & Neutral & & Disagree & \\
\hline & No & \% & No & \% & No & \% \\
\hline Eye can be donated after death & 183 & 89.3 & 14 & 6.8 & 8 & 3.9 \\
\hline Eye donation gives vision to blind people & 183 & 89.3 & 20 & 9.8 & 2 & 1 \\
\hline Eye donation is a noble work & 191 & 93.2 & 12 & 5.9 & 2 & 1 \\
\hline Living person pledge to donate eyes & 156 & 76.1 & 35 & 17.1 & 14 & 6.8 \\
\hline Willing to pledge your eyes? & 114 & 55.6 & 74 & 36.1 & 17 & 8.3 \\
\hline Willing to donate your eyes after death & 134 & 65.4 & 61 & 29.8 & 10 & 4.9 \\
\hline Eyes are not bought or sold & 103 & 50.2 & 62 & 30.2 & 40 & 19.5 \\
\hline Awareness regarding eye donation is important & 196 & 95.6 & 7 & 3.4 & 2 & 1 \\
\hline Donation of eyes lead to blindness in the next birth & 10 & 4.9 & 17 & 8.3 & 178 & 86.8 \\
\hline All blind people were cured by eye transplantation & 12 & 5.9 & 84 & 41 & 109 & 53.2 \\
\hline During transplant whole eye is used & 12 & 5.9 & 48 & 23.4 & 145 & 70.7 \\
\hline Eye donation disfigures the face of donor & 14 & 6.8 & 69 & 33.7 & 122 & 59.5 \\
\hline
\end{tabular}


Ratna Kumari Maharjan et.al. Knowledge and attitude regarding eye donation among students of Kathmandu university school of management; a cross-sectional online survey.

Table 7 shows that there is association between knowledge regarding eye donation and source of information which shows p-value is less than 0.05 and there is no association between other sociodemographic variables like gender, ethnicity and religion.

\begin{tabular}{|c|c|c|c|c|}
\hline \multirow{2}{*}{$\begin{array}{l}\text { Demographic } \\
\text { Variables }\end{array}$} & \multicolumn{3}{|c|}{ Level of Knowledge } & \multirow{2}{*}{$\begin{array}{c}\text { P-value } \\
\text { Fisher's exact test }\end{array}$} \\
\hline & Poor n $(\%)$ & Moderate n (\%) & Good n (\%) & \\
\hline \multicolumn{4}{|l|}{ Gender } & \multirow{3}{*}{0.652} \\
\hline Male & $23 \quad(31.9)$ & $47 \quad(65.3)$ & $2(2.8)$ & \\
\hline Female & $48 \quad(36.1)$ & $79(59.5)$ & $6(4.5)$ & \\
\hline \multicolumn{4}{|l|}{ Academic } & \multirow{3}{*}{0.211} \\
\hline BBA & $49(39.2)$ & $72(57.6)$ & $4(3.2)$ & \\
\hline MBA & $22(27.5)$ & $54(67.5)$ & $4(5)$ & \\
\hline \multicolumn{4}{|l|}{ Ethnicity } & \multirow{5}{*}{0.577} \\
\hline Newar & $36(38.3)$ & $53(56.4)$ & $5(5.3)$ & \\
\hline Bramin & $15(27.8)$ & $38(70.4)$ & $1(1.9)$ & \\
\hline Chhetri & $11(34.4)$ & $19(59.4)$ & $2(6.3)$ & \\
\hline Others & $9(36)$ & $16(64)$ & $0(0)$ & \\
\hline \multicolumn{4}{|l|}{ Religion } & \multirow{5}{*}{0.61} \\
\hline Buddhist & $10(35.7)$ & $16(57.1)$ & $2(7.1)$ & \\
\hline Hindu & $59(35.8)$ & $101(61.2)$ & $5(3)$ & \\
\hline Christian & $1(25)$ & $3(75)$ & $1(25)$ & \\
\hline Others & $1(12.5)$ & $6(75)$ & $1(12.5)$ & \\
\hline \multicolumn{4}{|c|}{ Source of Information } & \multirow{6}{*}{0.000} \\
\hline Internet & $52(49.1)$ & $53(50)$ & $1(0.9)$ & \\
\hline Newspaper & $1(25)$ & $3(75)$ & $0(0)$ & \\
\hline Tv/Radio & $8(22.9)$ & $26(74.3)$ & $1(2.9)$ & \\
\hline Friends/Relatives & $10(21.7)$ & $32(69.6)$ & $4(8.7)$ & \\
\hline Health worker & $0(0)$ & $12(85.7)$ & $2(14.2)$ & \\
\hline
\end{tabular}

\section{DISCUSSION}

In this study respondents of mean age was $22.71 \pm 2.65$ standard deviation. Most of the respondents were female $64.9 \%$, nearly half $45.9 \%$ of the respondents were from Newar ethnicity and more than $80.5 \%$ respondents were Hindu religion whereas $2.0 \%$ were Christian.

Present study findings showed that more than three fourth $77.1 \%$ had knowledge on eyes can be donate only after death which is consistent with descriptive study done in Uttarakhanda India with sample 375 in school children showed $77.3 \% .^{26}$ and contrast with cross sectional study done in KIST college, Nepal with sample 185 dental students showed only $31.4 \%{ }^{6}$ Finding of present study showed half of the respondents $51.2 \%$ were aware that cornea of the eyes is used for eye donation whereas three fourth of respondents $74.6 \%$ were aware in study done in uttarakhanda India ${ }^{26}$ and in cross sectional study done in KIST college, Nepal with sample 185 dental students showed nearly three fourth $71.9 \%{ }^{6}$ and present study nearly half $46.3 \%$ respondents know that corneal blind person is benefit by eye donation:

Present study finding on knowledge on eye can be donate by people of any age above one year was more than four fifth $88.7 \%$ and study consistent with descriptive study done in Uttarakhanda India with sample 375 in school children showed almost all $96 \% .^{26}$ and with cross sectional study done in KIST college, Nepal with sample 185 dental students showed nearly two third $60.5 \%{ }^{6}$.

In this study knowledge on high blood sugar and people having glasses can donate eyes were one fourth $27.5 \%$ and more than one third $38.2 \%$ respectively and this result is contrast with study done in descriptive study of Uttarakhanda India with sample 375 in school children showed more than four fifth $89.5 \%$ and almost all $93.8 \%$ respectively. $^{26}$

In present study knowledge about eye cannot donate by people with infection of cornea was $90.6 \%$ and people with Hepatitis B cannot donate eyes were $39.9 \%$ 
,this result contrast with study conducted in Uttarakhanda India with sample 375 in school children showed $76.5 \%{ }^{26}$.

In this study, almost all $99.0 \%$ of respondents said hospital is the place for donation eyes. One third $75.1 \%$ know that put wet cotton on eye lids after death and only $11.7 \%$ know that switch off the fan during event of death of person who willing to donate eyes. Maximum $86.3 \%$ of respondents said that Nepal Eye Donation Society is the approachable organisation for eye donation and $67.8 \%$ said eye bank is approachable organisation for eye donation, study contrast with cross sectional study carried out in KIST Medical college among 185 dental students, Nepal ${ }^{6}$ shows more than four fifty $82.7 \%$ did not know whom to contact for eye donation.

More than half $59.5 \%$ of the respondents have knowledge that eye should be donate within 6-8 hours after death ,this study contrast with cross sectional study carried out in KIST Medical college among 185 dental students ,Nepal shows only $37.8 \%{ }^{6}$

Almost all 93.7\% of respondents had knowledge on donation consent can be given by donor himself or herself when alive.

Regarding source of information in Present study shows that more than half of respondents $51.7 \%$ got information about eye donation from Internet followed by $2.0 \%$ from newspaper, study with Odisha cross sectional descriptive survey done in Odisha among 485 respondents, shows that they read about eye donation in newspapers $38.4 \%$,television internet $21 \%^{32}$ and also cross sectional study carried out in KIST Medical college among 185 dental students ,Nepal shows that $7.7 \%$ got information from newspaper and $24.3 \%$ from internet.

Present study shows the level of knowledge regarding eye donation. The result indicate that nearly two third of the respondents $(61.5 \%)$ have moderate knowledge, more than one third (34.6\%) of the respondents have poor knowledge and only few of the respondents $(3.9 \%)$ have good knowledge. Similar study was done among 681participants in Saudi Arabia that result shows $56.1 \%$ had poor knowledge, $40.9 \%$ had satisfied knowledge and only 2.95 had good knowledge ${ }^{30}$. Another study done in Mangalore, India shows contrast results done in 100 adolescents that $48 \%$ had good knowledge and only $1 \%$ had poor knowledge $^{7}$ and another study shows almost all $95.1 \%$ aware about eye donation and most of them were willing to donate their eyes in cross sectional study carried out in KIST Medical college among 185 dental students, Nepal ${ }^{6}$. Similarly descriptive cross-sectional study was carried out among 400 students of nursing college of Belagavi city India showed that $13 \%$ had poor knowledge, $57 \%$ had average and 30\% had good knowledge about eye donation ${ }^{32}$

In Present study shows that among 205 respondents $65.9 \%$ had good attitude regarding eye donation and 34\% had poor attitude regarding eye donation. Similarly study result supported that A communitybased, cross-sectional study was conducted on 760 adults in Gondar town, Northwest Ethiopia shows that $59.9 \%$ had good attitude and $40.1 \%$ had poor attitude regarding eye donation. ${ }^{17}$ Similarly descriptive cross-sectional study was carried out among 400 students of nursing college of Belagavi city India showed that $14.25 \%$ had poor Attitude, $71.75 \%$ had average and 14\% had good Attitude about eye donation $^{32}$.

Present study shows that there is association between knowledge regarding eye donation and source of information which shows p-value is less than 0.05 and there is no association between other sociodemographic variables like gender, ethnicity and religion. Similarly descriptive study done in 100 adolescents in Mangalore, India also shows that there is no significant association between knowledge score and demographic variables ${ }^{7}$.

\section{CONCLUSION}

This study has been concluding that most of the respondents had poor 
knowledge regarding eye donation. However, higher percentage of the respondents had good attitude. Information received from different source had significant association towards knowledge on eye donation but it seemed that though they received information from the media they could not answer correctly. It suggests that there is a need of community awareness program from health professionals.

\section{ACKNOWLEDGEMENT}

The authors express their sincere thanks to all the respondents for sparing their time to participate in this study. Also, the author would like to acknowledge the KUSOM College for giving opportunity to collect data and Entrepreneurship and Marketing, Associate Dean of KUSOM, Professor Binod Krishna Shrestha for valuable task and cooperation.

\section{Conflict of Interest: None}

\section{Source of Funding: None}

\section{Ethical Approval: Approved}

\section{REFERENCES}

1. Global Prevalence of Visual Impairment Corneal Blindness Treatment in Delhi Causes, Prevention ...https://www.eye7.in > cornea > corneal-blindness 2019

2. Blindness and vision impairment prevention WHO.2016

3. WJ Armitage, AB Tullo, DFP Larkin, The first successful full- thickness corneal transplant: a commentary on Eduard Zirm's landmark paper of $1906 \mathrm{Br} \mathrm{J}$ Ophthalmol. 2006 Oct; 90(10):1222-3 https://doi.org/10.1136/bjo.2006.101527

4. Eye bank association of America 2012. https://en.wikipedia.org/wiki/Eye_bank

5. National Eye Donation fortnight: 15 facts that you need to...https://www.thehealthsite.com > news , eye-donation-15-factsthat-you-need.. 3. Aug 24, 2018

6. Basnet A, Basnet PS, Lamichhane RS, Shrestha P. Awareness, knowledge and willingness regarding eye donation among dental students of KIST medical college and teaching hospital, Lalitpur, Nepal. Journal of Chitwan Medical College. 2019; 9(28):47-53. DOI: http://doi.org/ 10.3126/jcmc.v9i2.24533

7. Heyke M. Chacko, Jasmine Mathew, Jidiya Jose, Jisha Dominic, Sachina B.T. \& Babu D. Knowledge and Attitude regarding Eye Donation Among the Adolescents, Mangalore , Karnataka , INDIA Nitte University Journal of Health Science [march 2014],4(1)

8. Nepal Eye Bank Tilganga institute of ophthalmology, 2016

9. Shrestha P, Singh S K, D Hamal, Anwar A ,Awareness of eye donation among eye health workers Ophthalmologist, Nepal Eye Hospital, Kathmandu, Nepal Journal of Patan Academy of Health Sciences. 2018 Jun;5(1):16-21 .2018. DOI: 10.3126/jpahs.v5i1.24036

10. WHO.2016 Blindness and vision impairment prevention https://www.medindia.net/slide_shows/ey e_donation/slide3.html

11. Kurein, N. Awareness and knowledge on eye donation. American Journal of Advances in nursing research. [Online] 2016;3(2):85-88. Available from: http://mcmed.us/downloads/1471001159 (ajanr)pdf [Accessed 7 December 2019]. Retrieved from: www.mcmed.us/journal/ajanr

12. Gupta PC, Duggal M, Jamir L, Sharma D, Kankaria A, Sathyanath S, Kaur R, Rana K, Ram J, Knowledge and Attitude Toward Corneal Donation Among High School Children in Northern India Cornea. 2017 May;36(5):611-616. doi: 10.1097/ICO.0000000000001164.

13. https://m.dailyhunt.in/news/india/english/ my+medical+mantra+englishmedmanen/15+facts+about+eye+donation +you+must+know+about-newsid95403117

14. Estern Regional eye care program, Nepal 2007

15. Sigh,SK, Eye Donation awareness program. Retrieved from https://slideplayer.com/slide/12109994/

16. Venkata Ramana Ronanki, Sethu Sheeladevi, Brinda P Ramachandran, 
Ratna Kumari Maharjan et.al. Knowledge and attitude regarding eye donation among students of Kathmandu university school of management; a cross-sectional online survey.

Isabelle Jalbert. Awareness regarding eye donation among stakeholders in Srikakulam district in South India. BMC Ophthalmol. 2014 Mar 6;14:25. doi: 10.1186/1471-2415-14-25.

17. Hussen MS, Belete GT. Knowledge and attitude toward eye donation among adults, Northwest Ethiopia: A communitybased, cross-sectional study. Middle East Afr J Ophthalmol 2018; 25:126-30.

18. Anuradha Raj, Renu Dhasmana, Harsh Bahadur et al. Awareness, knowledge and attitude regarding eye donation in school going children in Uttarakhand. International journal of community Medicine and public health.2018 May;(5):1909-1915

19. Jena,P.,Jena,D.,Kar,M.,Jena,P., \& Nayek, R. A study on knowledge regarding eye donation among first year nursing students of a nursing school and college of Berhampur. Odisha, India. International Journal of Research in Medical Sciences; 2017 Nov;5(11):4942-4945 www.msjonline.org. DOI: http://dx.doi.org/10.18203/23206012.ijrms20174949

20. Sadana A. Sushma M. Chandra Lekha K. Shankar Ready D.Ravi Prabhu G. Ashok Kumar Reddy K. Assessment Of Knowledge And Attitude Regarding Eye Donation Among Undergraduate Medical Students, Tirupati Int J Med Pharm Sci, May 2014 / Vol 04 (09)

21. Panigrahi S. Rath B. Sahu R.K. Rath S. SethiS.K. Mahapatra K. Knowledge, Attitude and Willingness for Eye Donation in General Population of Odisha in Eastern India IOSR Journal of Dental and Medical Sciences (IOSR-JDMS) eISSN: 2279-0853, p-ISSN: 22790861. Volume 16, Issue 7 Ver. I (July. 2017), PP 01-06 www.iosrjournals.org

22. Maiyal G R. Kiran K.G. Sanjeev B. Assessment of awareness and perception regarding eye donation among selected patients attending field practice area of a tertiary care hospital in Mangalore:a cross sectional study International Journal of Community Medicine and Public Health 2018 Jul;5(7):2920-2925 http://www.ijcmph.com

DOI: http://dx.doi.org/10.18203/2394-

6040.ijcmph20182623

23. Araya S.D.Gupta N.Malik A.Eye donation awareness among medical and paramedical staff in a medical institute. Government Medical College and Hospital, Chandigarh, India Nepal J Ophthalmol 2014; 6(12): 177-184

24. Paraz CM, Truong HT, Sai DK, CajucomUy HY, Chan CL, Kassim SM. Knowledge and attitudes toward corneal donation among Singaporean youth: a cross-sectional study. Eye and Vision. 2016 Dec;3(1):1-0.Zahid MZ, Kumar A. Awareness and perception regarding eye donation among under graduate medical College Student in South Western Bihar. International Journal of Health and Clinical Research. 2021 Mar 16;4(5):31721.

25. Raj A.Dharsman R.Bahadur H.Bhandari S.S.Awarness knowledge and attitude regarding Eye Donation in school children in uttarakhand International Journal of Community Medicine and Public Health 2018 http://www.ijcmph.com

26. Hameed N, Jadidy E. Knowledge and attitude regarding eye donation and corneal transplantation among medical students of Taibah University in Medina, Saudi Arabia 2015. Int J Acad Sci Res. 2015;3(4):18-26.

27. Alem S, Siddiqui M. Knowledge and Attitudes Regarding Eye Donation and Corneal Transplants In Saudi Arabia: A Cross-Sectional Study. Age.;20(70):18-7.

28. Sushma H, Warad VG, Kshetrapal M. Knowledge, attitude and practice about eye donation among medical and paramedical students in tertiary eye care hospital. Kerala Journal of Ophthalmology. 2016 Apr 1;28(2):112. DOI: 10.4103/kjo.kjo_30_16

29. Alanazi LF, Aldossari SH, Gogandy MA, Althubaiti GA, Alanazi BF, Alfawaz AM. Attitude, beliefs and awareness towards corneal donation in Saudi Arabia. Saudi Journal of Ophthalmology. 2019 Apr 1;33(2):121-9.

DOI: $10.1016 /$ j.sjopt.2019.02.003 
Ratna Kumari Maharjan et.al. Knowledge and attitude regarding eye donation among students of Kathmandu university school of management; a cross-sectional online survey.

30. Bugis A, Ali A, Almaghrabi A, Alharbi A, Fatani Y, Alem S, Siddiqui $M$. Knowledge and attitudes regarding eye donation and corneal transplants in Saudi Arabia a cross-sectional study. Int $\mathbf{J}$ Medical Res Profession. 2018 Jan;4(1); 272-5.

31. Panigrahi S, Sahu RK, Jali SN, Rath B, Pati S, Kerketta M. Knowledge, attitude and practice regarding diabetic retinopathy among medical and nursing students of a tertiary care teaching hospital of Odisha: a cross sectional study. IOSR J Dent Med Sci. 2017;16:1-7.

32. Subodh KumarYadav, S.B. Patil, Ashiwini. B. Narasannavar, Mubashir Angolkar. Knowledge and Attitude
Regarding Eye Donation among Undergraduate Nursing Students of Belagavi city: A Cross-Sectional Study International Journal of Interdisciplinary and Multidisciplinary Studies (IJIMS), 2015, Vol 2, No.8,17-23. 17

Available online at http://www.ijims.com ISSN: $2348-0343$

How to cite this article: Maharjan RK, Bajracharya N, Awale S. Knowledge and attitude regarding eye donation among students of Kathmandu University school of management; a cross-sectional online survey. Int J Health Sci Res. 2021; 11(5): 313-322. DOI: https://doi.org/10.52403/ijhsr.20210549 